7

8

\title{
Albendazole solid dispersions against alveolar echinococcosis: a pharmacotechnical strategy to improve the efficacy of the drug
}

3

Julia Fabbri a,d, Patricia Eugenia Pensel a,d, Clara María Albani a,d, Lurdes Milagros Lopez a, Analia Simonazzi b,d, José María Bermudez b,d, Santiago Daniel Palma c,d, María Celina Elissondo a,d,*

a Laboratorio de Zoonosis Parasitarias, Instituto de Investigaciones en Producción, Sanidad y Ambiente (IIPROSAM), Facultad de Ciencias Exactas y Naturales (FCEyN), Universidad Nacional de Mar del Plata (UNMdP), Mar del Plata, Buenos Aires, 1 Argentina.

b Instituto de Investigaciones para la Industria Química, Universidad Nacional de Salta (UNSa), Salta, Argentina.

c Laboratorio de Farmacotecnia, Facultad de Ciencias Químicas (FCQ), Universidad Nacional de Córdoba (UNC), Córdoba, Argentina.

d Consejo Nacional de Investigaciones Científicas y Técnicas (CONICET), Buenos Aires, Argentina.

Running title: Albendazole solid dispersions against Echinococcus multilocularis

* Corresponding author:

María Celina Elissondo. Laboratorio de Zoonosis Parasitarias, Instituto de Investigaciones en Producción, Sanidad y Ambiente (IIPROSAM), Facultad de Ciencias Exactas y Naturales, Universidad Nacional de Mar del Plata (UNMdP), Funes 3250, 7600 Mar del Plata, Argentina. Tel.: +54 223475 2426. Fax: +54 223475 3150. E-mail address: c.elissondo@gmail.com 


\section{Abstract}

Alveolar echinococcosis is a neglected parasitic zoonosis caused by Echinococcus multilocularis. The pharmacological treatment is based on albendazole (ABZ). However, the low water solubility of the drug produces a limited dissolution rate, with the consequent failure in the treatment of the disease. Solid dispersions are a successful pharmacotechnical strategy to improve the dissolution profile of poorly water soluble drugs. The aim of this work was to determine the in vivo efficacy of ABZ solid dispersions using poloxamer 407 as a carrier (ABZ:P407 SDs) in the murine intraperitoneal infection model for secondary alveolar echinococcosis. In the chemoprophylactic efficacy study, the ABZ suspension, the ABZ:P407 SDs and the physical mixture of $\mathrm{ABZ}$ and poloxamer 407 showed a tendency to decrease the development of murine cysts, causing damage to the germinal layer. In the clinical efficacy study, the ABZ:P407 SDs produced a significant decrease in the weight of murine cysts. In addition, the SDs produced extensive damage to the germinal layer. The increase in the efficacy of ABZ could be due to the improvement of water solubility and wettability of the drug due to the surfactant nature of poloxamer 407 . In conclusion, this study is the basis for further research. This pharmacotechnical strategy might in the future offer novel treatment alternatives for human alveolar echinococcosis.

\section{Keywords}

Echinococcus multilocularis; alveolar echinococcosis; albendazole; solid dispersions; poloxamer 
49

50

51

52

53

54

55

56

57

58

56

\section{Key Findings}

- Albendazole (ABZ) solid dispersions showed higher efficacy than ABZ against murine alveolar echinococcosis.

- This is a consequence of the increase in the dissolution rate of ABZ that could impact on improvement in bioavailability.

- ABZ solid dispersions could represent an alternative strategy for future treatment against alveolar echinococcosis. 


\section{Introduction}

0

(1)
the metacestode stage of Echinococcus multilocularis, which represents an important public health threat. This parasite is predominantly maintained in a wildlife cycle, with carnivores as definitive hosts and small mammals as intermediate hosts. Humans acquire the infection by ingesting eggs shed in the feces of a definitive host and develop the metacestode stage, which is characterised by a tumour-like and infiltrative growth. If not appropriately treated, parasite expansion will eventually lead to organ failure and death of the patient (Kern et al., 2017).

The metacestode stage is composed of numerous small vesicles with a wall structure formed by an outer acellular laminated layer and an internal cellular layer called germinal layer (Eckert and Deplazes, 2004). A special cell type in the germinal layer, the germinative cells, are responsible for the high regenerative potential of the parasite (Kern et al., 2017).

There are several approaches to the management of AE. In patients with viable cysts, the treatment of choice is the total removal of the cystic lesion combined with oral treatment with $15 \mathrm{mg} / \mathrm{kg} /$ day of albendazole (ABZ) for two years. In inoperable patients, prolonged treatment with $\mathrm{ABZ}$ should be carried out to decrease the proliferation of E. multilocularis. In cases of calcified or negative lesions by Fluorodeoxyglucose (FDG) Positron Emission Tomography (PET), the patient should be periodically monitored (watch and wait) (Wen et al., 2019).

For an effective treatment in systemic infections, the drug must be sufficiently soluble in water to easily reach the cell membrane, but also hydrophobic enough to cross it (Thompson, 1997). The biopharmaceutical classification system categorizes $\mathrm{ABZ}$ as a class 2 drug due to its low aqueous solubility and high permeability (Kasim et 
al., 2004). These characteristics produce a limited dissolution rate resulting in a poor and erratic bioavailability of ABZ (Marriner et al., 1986; Edwards and Breckenridge, 1988; Castro et al., 2009). Due to the low concentration of drug reaching the parasite, $\mathrm{ABZ}$ acts as a parasitostatic rather than as a parasitocidal agent for many cases, and the recurrence rates after interruption of therapy are high (Reuter et al., 2004). Consequently, the treatment must be carried out with high daily doses of ABZ for prolonged periods, with the risk of low adherence to the treatment and the possibility of adverse effects (Bardonnet et al., 2013; Kern et al., 2017). Moreover, another explanation for the parasitostatic effect of ABZ on germinative cells is that they may specifically express a $\beta$-tubulin isoform with limited affinity to benzimidazoles (Brehm and Koziol, 2014).

The development of new $\mathrm{ABZ}$ formulations that improve its solubility is essential to increase the effectiveness of pharmacological treatment. Until now, several pharmacotechnical strategies to increase bioavailability and, consequently, the effectiveness of $\mathrm{ABZ}$ have been evaluated in murine models of cystic and alveolar echinococcosis: incorporation of ABZ into liposomes (Dvorožňáková et al., 2004; Lv et al., 2012), ABZ loaded in lipid nanocapsules (Pensel et al., 2015; Ullio Gamboa et al., 2019), nanocrystal and nanocrystalline formulations of ABZ (Pensel et al., 2018; Hu et al., 2019), solid dispersions of ABZ with poloxamer 188 (Pensel et al., 2014) and ABZchitosan microspheres (Abulaihaiti et al., 2015).

The solid dispersions (SDs) are a successful strategy to improve the dissolution profile of poorly water soluble drugs. This strategy is currently widely used in therapeutics, which is reflected in numerous commercialized products. For example, Sporanox ${ }^{\circledR}$, Onmel ${ }^{\circledR}$ and Gris-PEG ${ }^{\circledR}$ are used as antifungals, whereas Kaletra ${ }^{\circledR}$, Intelence ${ }^{\circledR}$ and Norvir ${ }^{\circledR}$ are indicated in combination with other antiretroviral agents for 
the treatment of HIV. On the other hand, Isoptin $\mathrm{SR}^{\circledR}$, Nivadil ${ }^{\circledR}$, Afeditab $\mathrm{CR}^{\circledR}$ and Adalat-XL ${ }^{\circledR}$ are indicated for the treatment of heart conditions, Cesamet ${ }^{\circledR}$ is used as antiemetic and Kalydeco ${ }^{\circledR}$ is indicated for cystic fibrosis (Cid et al., 2019).

The SDs are molecular mixtures of drugs and inert carriers, prepared by the fusion method and/or solvent method (Chiou and Riegelman, 1971). According to the physical state of the carrier, SDs are classified into four generations (Vasconcelos et al, 2007). In the third generation of SDs, surfactants or emulsifiers are used as carriers, which improve the dissolution profile and the physical and chemical stability of the drug (Desai et al., 2006). These SDs were more stable mainly due to a reduction of drug recrystallization (Vasconcelos et al, 2007).

Poloxamers, nonionic surfactants with solubilizing properties, are suitable for most of the standard procedures used to prepare SDs because of their polymeric nature. In addition, they are not metabolized in the body (Collett and Popli, 2000). Poloxamer 407 (P407) is accepted by the FDA as an inactive ingredient for different types of preparations (e.g., intravenous, inhalation, oral solution, suspension, ophthalmic or topical formulations) (Rowe et al., 2005). Simonazzi et al. (2018) designed ABZ SDs using P407 as carrier (ABZ:P407 SDs). These SDs markedly improved ABZ solubility and dissolution rate compared with pure $\mathrm{ABZ}$ and a commercial formulation. These drug-related factors affect the gastrointestinal absorption thus improving the bioavailability. In this context, the aim of the current work was to determine the in vivo efficacy of ABZ:P407 SDs in the murine model of AE.

\section{Materials and methods}

Preparation of solid dispersions and physical mixtures 
134 Simonazzi et al. (2018) ensuring quality in terms of physicochemical properties and 135 dose adjustment. Briefly, ABZ (Pharmaceutical grade, Parafarm, Argentina) was 136 homogeneously dispersed in the molten P407 (BASF®, Germany) at 63 degrees (1:1), 137 by stirring. The preparation was rapidly cooled in liquid nitrogen, pulverized and sieved. The $210 \mu \mathrm{m}$ particle size fraction was kept in a glass vial at room temperature until use.

Physical mixtures were prepared from ABZ and P407 previously sieved (210 $\mu \mathrm{m}$ particle size fraction). The components were mixed in equal proportions in a Laboratory-scale V-blender for $5 \mathrm{~min}$. The powders were stored in a glass vial at room temperature until use.

Preparation of ABZ formulations

The suspension of ABZ $(3.08 \mathrm{mg} / \mathrm{ml})$ was prepared by dispersion of pure ABZ in distilled and deionized water $(\mathrm{pH}=7.0)$ with carboxymethylcellulose (CMC, Todo Droga, Córdoba, Argentina) $(0.5 \% \mathrm{w} / \mathrm{v}, \mathrm{pH}=6.0)$. The suspension was shaken for $5 \mathrm{~h}$ and sonicated for $1 \mathrm{~h}$. The ABZ:P407 SDs $(6.16 \mathrm{mg} / \mathrm{ml})$, physical mixture $(6.16 \mathrm{mg} / \mathrm{ml})$ and P407 (3.08 $\mathrm{mg} / \mathrm{ml})$ suspensions were prepared by dissolution in distilled and deionized water $(\mathrm{pH}=7.0)$ under shaking $(5 \mathrm{~h})$. All formulations were stored at $4{ }^{\circ} \mathrm{C}$ and were vigorously shaken before administration to mice.

Parasite material

The studies were carried out using E. multilocularis isolate J2012 (kindly provided by Klaus Brehm, Institute for Hygiene and Microbiology, University of 
secondary AE, the parasite was propagated in the peritoneum of CF-1 mice and was processed as described by Albani et al. (2015), with some modifications. Briefly, the metacestodes obtained from the peritoneal cavity of the animals were cut to obtain a parasitic suspension. The suspension was passed through a metallic strainer and washed several times with phosphate-buffered saline (PBS). Finally, 0.5 vol of PBS and 12 $\mu \mathrm{g} / \mathrm{ml}$ of ciprofloxacin (Roemmers, Argentina) were added to parasite tissue and incubated overnight at $4{ }^{\circ} \mathrm{C}$ (Spiliotis and Brehm, 2009).

Experimental design and evaluation of in vivo efficacy of ABZ:P407 SDs against the murine model of $\mathrm{AE}$ were intraperitoneally infected with $0.3 \mathrm{ml}$ of homogenized parasitic material of $E$. multilocularis in PBS ( $\mathrm{n}=50$ for each study). In the chemoprophylactic efficacy study, the dosage of the animals began 1 day post-infection, while in the clinical efficacy study the treatment began 6 weeks post-infection. In each study, the experimental groups were: 1- water control group, mice received distilled and deionized water as a placebo; 2- P407 control group, mice received P407 suspended in distilled and deionized water; 3- ABZ-CMC group, mice were treated with a suspension of ABZ in distilled and deionized water with $\mathrm{CMC}$; 4- Physical mixture group, the animals received a suspension of physical mixture (ABZ and P407, 1:1); 5- ABZ:P407 SDs group, animals were treated with a suspension of ABZ:P407 SDs. The animals were randomly distributed into the treatment groups (10 animals/group) with 5 mice per cage.

In both studies, treatments were performed daily for 30 days by intragastric $\mathrm{mg} / \mathrm{kg}$ per day. 
Approximately 10 weeks post-infection, the mice were anesthetized with 100

184

$\mathrm{mg} / \mathrm{kg}$ of ketamine and $10 \mathrm{mg} / \mathrm{kg}$ of xylazine and subsequently euthanized by cervical dislocation and necropsied. The cystic masses were obtained from the peritoneal cavity of each mouse and weighed. The median cysts weight from each group and ultrastructural study of the germinal layer of cysts by scanning electron microscopy were used to determine the efficacy of each treatment (Albani et al, 2015).

\section{Scanning electron microscopy}

Samples of cysts obtained from animals involved in both in vivo efficacy studies were processed for scanning electron microscopy as described by Elissondo et al. (2007). Briefly, samples were fixed in 3\% glutaraldehyde (Sigma-Aldrich, St. Louis, USA) in 0.1 M sodium cacodylate buffer pH 7.4 (Sigma-Aldrich, St. Louis, USA) for $72 \mathrm{~h}$ at $4^{\circ} \mathrm{C}$. Then, several washes in $0.1 \mathrm{M}$ sodium cacodylate buffer were made. After that, the specimens were dehydrated by sequential incubations of $10 \mathrm{~min}$ in increasing concentrations of ethanol (Cicarelli, Argentina): 50\%, 70\%, 80\%, 90\%, 95\%, and twice in $100 \%$. Finally, samples were immersed in hexamethyldisilazane (Sigma-Aldrich, St. Louis, USA) for $5 \mathrm{~min}, 1 \mathrm{~h}$, and overnight. They were then sputter-coated with gold (100- $\AA$ thickness) and inspected on a JEOL JSM-6460 LV scanning electron microscope operating at $15 \mathrm{kV}$.

\section{Statistical analysis}

Cysts weights of the different groups, reported as median and interquartile range (IQR), were compared by Kruskal Wallis Test (nonparametric method) followed by Dunn's Multiple Comparisons Test. The analysis was carried out using Instat 3.0 
207 software program (GraphPad Software, San Diego, CA, USA). In all cases, P values 208 less than $0.05(\mathrm{P}<0.05)$ were considered statistically significant.

\section{Results}

Chemoprophylactic efficacy study of ABZ:P407 SDs against the murine model of AE developed cystic masses in the abdominal cavity. No significant differences were found $(\mathrm{P}>0.05)$ between the median weight of the cysts of the water and $\mathrm{P} 407$ control groups.

Although the median weight of cysts recovered from mice treated with all formulations of $\mathrm{ABZ}$ were lower in relation to the control groups, no significant differences were detected $(\mathrm{P}>0.05$, Table 1$)$.

The ultrastructural study of the germinal layer of metacestodes recovered from control and treated groups is shown in Fig. 1. The germinal layer of cysts obtained from control mice showed the characteristic multicellular structure (Fig. 1a). The decrease in the weight of the cysts belonging to treated groups was correlated with ultrastructural alterations observed by scanning electron microscopy. Areas without cells in the germinal layer were observed in treated cysts (Figs. 1b-d).

Clinical efficacy study of ABZ:P407 SDs against the murine model of AE

Table 2 summarizes the cyst weights (median and IQR) recorded after treatments of the different experimental groups involved in therapeutic efficacy study. There were no statistically significant differences $(\mathrm{P}>0.05)$ between the median cyst weights of control groups (i.e. water and P407 control groups). Although the median weight of cysts recovered from $\mathrm{ABZ}-\mathrm{CMC}$ and physical mixture groups were lower than those observed in the control groups, no differences were found between treated 
232

233

groups and control groups $(\mathrm{P}>0.05)$. In contrast, ABZ:P407 SDs treatment caused a significant decrease in the cysts weight compared with control groups $(\mathrm{P}<0.05)$.

Metacestodes recovered from treated mice showed damage in the germinal layer, in relation to the control groups. However, the damage extension appears to be greater after ABZ:P407 SDs compared to the ABZ-CMC treatment (Fig. 2).

\section{Discussion}

The drug of choice for the pharmacological treatment of human echinococcosis is ABZ. As this drug was developed primarily to target parasites in the gastrointestinal tract, a low bioavailability outside the intestine was considered important for its optimal performance. However, this feature is considered undesirable for a systemic parasitic disease as echinococcosis (Shuhua et al., 2002). The expression of a $\beta$-tubulin isoform with limited affinity to benzimidazoles by germinative cells and the low concentrations of $\mathrm{ABZ}$ reaching the parasite produce a parasitostatic effect and relapses after chemotherapy have been reported (Reuter et al., 2004; Brehm and Koziol, 2014).

The gastrointestinal permeability and solubility of some drugs are limiting conditions for oral absorption, directly affecting their bioavailability. Although permeability is an intrinsic property of a drug, different strategies have been developed for improving the dissolution rate with the aim of designing suitable formulations for oral administration (Vo et al., 2013). Scientific evidence indicates that a higher drug bioavailability correlates with an improved efficacy of benzimidazoles against murine echinococcosis (Mingjie et al., 2002; Shuhua et al., 2002; Dvorožňáková et al., 2004; Ceballos et al., 2006, 2008, 2009; Liu et al., 2012; Abulaihaiti et al., 2015; Hu et al., 2019). 

(Amidon et al., 1995). Simonazzi et al. (2018) demonstrated that the use of P407 as carrier in ABZ SDs markedly improved its solubility and dissolution rate compared with pharmaceutical grade $\mathrm{ABZ}$ and a commercial formulation. In addition, it was observed that the polymer maintained a desirable level of a supersaturation state in the dissolution medium. This was reached by preventing solvent-mediated crystallization over the time period necessary for the absorption process. The results observed in vitro with the ABZ:P407 SDs could be correlated with the efficacy obtained in the present study in the murine model of AE.

During the chemoprophylactic efficacy study, all formulations of ABZ showed a tendency to decrease the development of E. multilocularis cysts. The ultrastructural study of metacestodes supports these results, showing the loss of cells of the germinal that a significant protection against protoscoleces of E. granulosus was achieved in gerbils by one month treatment of ABZ $(10 \mathrm{mg} / \mathrm{kg} / \mathrm{day})$. In the clinical efficacy study, the ABZ:P407 SDs achieved a statistically significant decrease in the weight of cysts, with an efficacy of $86 \%$. In addition, the extent of damage caused by ABZ:P407 SDs was greater compared to the other treated groups. The ultrastructural alterations in the germinal layer were similar to those observed in mice infected with E. granulosus treated with other benzimidazoles (Ceballos et al., 2009, 2010). Our results are consistent with those reported by Pensel et al. (2014), who demonstrated a greater in vivo efficacy of ABZ formulated as SDs using P188 in the murine model of cystic echinococcosis. 
The SDs increase the dissolution rate of low water soluble drugs (Vo et al.,

281 2013). The enhanced efficacy obtained after oral administration of ABZ:P407 SDs could be explained by an increase in ABZ dissolution rate caused by the surfactant nature of poloxamers. Poloxamers in certain concentrations form micelles with a hydrophobic core which could incorporate insoluble molecules as ABZ, promoting faster and more complete solubility, increasing ABZ bioavailability and efficacy (Kabanov et al., 2002). On the other hand, the humectability effect of the surfactant could create a favorable microenvironment around the drug particles that would facilitate the dissolution process (Chen et al., 2004). In this way, poloxamers would improve water solubility and wettability of ABZ.

In terms of drug safety, $\mathrm{ABZ}$ has been extensively investigated in a wide range of antiparasitic indications. At low dose, the incidence of adverse experiences is low. At the higher doses and more prolonged exposure used in the treatment of echinococcosis, there is an increase in the number and severity of adverse experiences. Adverse effects include nausea, vomiting, diarrhea, dizziness, headache, neutropenia, liver toxicity, alopecia and others (Horton, 1997; Brunetti et al., 2010). The ABZ SDs formulations would allow administering lower doses of drug in the treatment of echinococcosis, with the consequent reduction in side effects. Paredes et al. (2018) reported ABZ selfdispersible nanocrystals achieve the same efficacy against a model intestinal nematode parasite in dogs using a dose which was four times lower than a commercial formulation.

This pharmacotechnical strategy might in the future offer novel treatment alternatives for human $\mathrm{AE}$. In a next step, we will characterize the pharmacokinetic profile after the administration of ABZ:P407 SDs in mice infected with $E$. multilocularis. 
Acknowledgments. The authors thank Alejandra Goya, Sonia Ortega and

Carolina Kelly (SENASA, Argentina). The authors also wish to thank Dr. Mauro

Chaparro (UNMdP-CONICET) for his assistance in the statistical study.

Financial Support. This study was financially supported by the PICT 15 No.

0717 (Agencia Nacional de Promoción Científica y Tecnológica, Argentina), EXA

769/16 and EXA 871/18 (Universidad Nacional de Mar del Plata, Argentina).

Ethical standards. Six-eight weeks old female CF-1 mice (body weight $25 \mathrm{~g} \pm$

5) were used. The animals were housed in a room with temperature-controlled (22 \pm 1

${ }^{\circ} \mathrm{C}$ ), a relative air humidity of $50 \pm 5 \%$, and a cycle of $12 \mathrm{~h}$ light and $12 \mathrm{~h}$ dark. Food and water were given ad libitum. Animal procedures and management protocols were approved by the Institutional Animal Care and Use Committee (RD 211/18) of the Faculty of Exact and Natural Sciences, National University of Mar del Plata, Mar del Plata, Argentina and carried out in accordance with the revised form of The Guide for the Care and Use of Laboratory Animals (National Research Council US, 2011). Unnecessary animal suffering was avoided throughout the study. 


\section{References}

Abulaihaiti M, Wu XW, Qiao L, Lv HL, Zhang HW, Aduwayi N, Wang YJ, Wang XC and Peng XY (2015) Efficacy of albendazole-chitosan microsphere-based treatment for alveolar echinococcosis in mice. PLoS Neglected Tropical Disease 9(9), e0003950.

Albani CM, Pensel PE, Elissondo N, Gambino G and Elissondo MC (2015) In vivo activity of albendazole in combination with thymol against Echinococcus multilocularis. Veterinary Parasitology 212, 193-199.

Amidon GL, Lennernäs H, Shah VP and Crison JR (1995) A theoretical basis for a biopharmaceutic drug classification: the correlation of in vitro drug product dissolution and in vivo bioavailability. Pharmaceutical Research 12(3), 413-420.

Bardonnet K, Vuitton DA, Grenouillet F, Mantion GA, Delabrousse E, Blagosklonov O, Miguet JP and Bresson-Hadni S (2013) 30-yr course and favorable outcome of alveolar echinococcosis despite multiple metastatic organ involvement in a non-immune suppressed patient. Annals of Clinical Microbiology and Antimicrobials 12(1), 1.

Brehm K and Koziol U (2014) On the importance of targeting parasite stem cells in anti-echinococcosis drug development. Parasite 21,72.

Brunetti E, Kern P and Vuitton DA (2010) Expert consensus for the diagnosis and treatment of cystic and alveolar echinococcosis in humans. Acta Tropica 114, 116.

Castro N, Márquez-Caraveo C, Brundage RC, González-Esquivel D, Suárez AM, Góngora F, Jara A, Urizar J, Lanao JM and Jung H (2009) Population pharmacokinetics of albendazole in patients with neurocysticercosis. International Journal of Clinical Pharmacology and Therapeutics 47, 679-685. 
Ceballos L, Alvarez L, Sánchez Bruni S, Elissondo MC, Dopchiz M, Denegri G, Torrado J and Lanusse CE (2006) Development of a cyclodextrin-based flubendazole formulation to control secondary echinococcosis: pharmacokinetics, hydatid cyst morphology and efficacy in mice. Journal of Veterinary Pharmacology and Therapeutics 29, 85-86.

Ceballos L, Elissondo MC, Moreno L, Dopchiz M, Sánchez Bruni S, Denegri G, Alvarez L and Lanusse CE (2008) Albendazole treatment in cystic echinococcosis: pharmacokinetics and clinical efficacy of two different aqueous formulations. Parasitology Research 103, 355-362.

Ceballos L, Elissondo MC, Sánchez Bruni S, Confalonieri A, Denegri G, Alvarez L and Lanusse CE (2010) Chemoprophylactic activity of flubendazole in cystc echinococcosis. Chemotherapy 56, 386-392.

Ceballos L, Elissondo MC, Sánchez Bruni S, Denegri G, Alvarez L and Lanusse CE (2009) Flubendazole in cystic echinococcosis therapy: pharmacoparasitological evaluation in mice. Parasitology International 58, 354-358.

Chen Y, Zhang GGZ, Neilly J, Marsh K, Mawhinney D and Sanzgiri YD (2004) Enhancing the bioavailability of ABT-963 using solid dispersion containing pluronic F-68. International Journal of Pharmaceutics 286, 69-80.

Chiou WL and Riegelman S (1971) Pharmaceutical applications of solid dispersion systems. Journal of Pharmaceutical Sciences 60(9), 1281-1302.

Cid AG, Simonazzi A, Palma SD and Bermúdez JM (2019) Solid dispersion technology as a strategy to improve the bioavailability of poorly soluble drugs. Therapeutic Delivery 10(6), 363-382.

Collett JH and Popli H (2000) Poloxamer. In Kibbe, AH (ed.). Handbook of pharmaceutical excipients. Pharmaceutical Press, London, pp. 385-388. 
Desai J, Alexander K and Riga A (2006) Characterization of polymeric dispersions of dimenhydrinate in ethyl cellulose for controlled release. International Journal of Pharmaceutics 308(1), 115-123.

Dvorožňáková E, Hrčková G, Borošková Z, Velebný S and Dubinský P (2004) Effect of treatment with free and liposomized albendazole on selected immunological parameters and cyst growth in mice infected with Echinococcus multilocularis. Parasitology International 53(4), 315-325.

Eckert J and Deplazes P (2004) Biological, epidemiological, and clinical aspects of Echinococcosis, a zoonosis of increasing concern. Clinical Microbiology Reviews 17, 107-135.

Edwards G and Breckenridge A (1988) Clinical pharmacokinetics of anthelmintic drugs. Clinical Pharmacokinetics 15, 67-93.

Elissondo MC, Ceballos L, Dopchiz M, Andresiuk V, Alvarez L, Sánchez Bruni S, Lanusse C and Denegri G (2007) In vitro and in vivo effects of flubendazole on Echinococcus granulosus metacestodes. Parasitology Research 100, 1003-1009.

Horton RJ (1997) Albendazole in treatment of human cystic echinococcosis: 12 years of experience. Acta Tropica 64, 79-93.

Hu C, Liu Z, Liu C, Zhang Y, Fan H and Qian F (2019) Improvement of antialveolar echinococcosis efficacy of albendazole by a novel nanocrystalline formulation with enhanced oral bioavailability. ACS Infectious Diseases https://doi.org/10.1021/acsinfecdis.9b00231

Kabanov AV, Batrakova EV and Alakhov VY (2002) Pluronic ${ }^{\circledR}$ block copolymers as novel polymer therapeutics for drug and gene delivery. Journal of Controlled Release 82(2-3), 189-212. 
Kasim NA, Whitehouse M, Ramachandran C, Bermejo M, Lennernäs H, Hussain AS, Junginger HE, Stavchansky SA, Midha KK, Shah VP and Amidon GL (2004) Molecular properties of WHO essential drugs and provisional biopharmaceutical classification. Molecular Pharmaceutics 1(1), 85-96.

Kern P, Menezes da Silva A, Akhan O, Müllhaupt B, Vizcaychipi KA, Budke C and Vuitton DA (2017) The echinococcoses: diagnosis, clinical management and burden of disease. In Thompson, RCA, Deplazes, P and Lymbery, AJ (eds.). Advances in parasitology. Echinococcus and Echinococcosis, Part B. Elsevier, Academic Press, vol. 96, pp. 259-369.

Liu C, Zhang H, Jiang B, Yao J, Tao Y, Xue J and Wen A (2012) Enhanced bioavailability and cysticidal effect of three mebendazole-oil preparations in mice infected with secondary cysts of Echinococcus granulosus. Parasitology Research 111, 1205-1211.

Lv H, Jiang Y, Liao M, Sun H, Zhang S and Peng X (2013) In vitro and in vivo treatments of Echinococcus granulosus with Huaier aqueous extract and albendazole liposome. Parasitology Research 112(1), 193-198.

Marriner E, Morris DL, Dickson B and Bogan JA (1986) Pharmacokinetics of albendazole in man. European Journal of Clinical Pharmacology 30, 705-708.

Mingjie W, Shuhua X, Junjie C, Bin L, Cheng F, Weixia S and Hotez P (2002) Albendazole-soybean oil emulsion for the treatment of human cystic echinococcosis: evaluation of bioavailability and bioequivalence. Acta Tropica 83, 177-181.

Morris DL and Taylor DH (1988) Optimal timing of post-operative albendazole prophylaxis in E. granulosus. Annals of Tropical Medicine and Parasitology 82(1), 65-66. 
National Research Council US (2011) Guide for the care and use of laboratory animals, 8th ed. National Academies Press, US, Washington DC.

\section{Paredes AJ, Litterio N, Dib A, Allemandi DA, Lanusse C, Sánchez Bruni S and} Palma SD (2018) A nanocrystal-based formulation improves the pharmacokinetic performance and therapeutic response of albendazole in dogs. Journal of Pharmacy and Pharmacology 70, 51-58.

Pensel PE, Paredes A, Albani CM, Allemandi D, Sanchez Bruni S, Palma SD and Elissondo MC (2018) Albendazole nanocrystals in experimental alveolar echinococcosis: Enhanced chemoprophylactic and clinical efficacy in infected mice. Veterinary Parasitology 251, 78-84.

Pensel PE, Castro S, Allemandi D, Sánchez Bruni S, Palma SD and Elissondo MC (2014) Enhanced chemoprophylactic and clinical efficacy of albendazole formulated as solid dispersions in experimental cystic echinococcosis. Veterinary Parasitology 203(1-2), 80-86.

Pensel PE, Ullio Gamboa G, Fabbri J, Ceballos L, Sanchez Bruni S, Alvarez LI, Allemandi D, Benoit JP, Palma SD and Elissondo MC (2015) Cystic echinococcosis therapy: Albendazole-loaded lipid nanocapsules enhance the oral bioavailability and efficacy in experimentally infected mice. Acta Tropica 152, $185-194$.

Reuter S, Buck A, Manfras B, Kratzer W, Seitz HM, Darge K, Reske SN and Kern P (2004) Structured treatment interruption in patients with alveolar echinococcosis. Hepatology 39, 509-517.

Rowe R, Sheskey P and Owen S (2005) Handbook of pharmaceutical excipients, 5th Edn. Pharmaceutical, London UK and American Pharmaceutical Association, Washington, USA. 
Shuhua X, Jiqing Y, Mingjie W, Pieying J, Fanghua G, Junjie C, Wei J and Hotez P (2002) Augmented bioavailability and cysticidal activity of albendazole reformulated in soybean emulsion in mice infected with Echinococcus granulosus or Echinococcus multilocularis. Acta Tropica 82, 77-84.

\section{Simonazzi A, Cid AG, Paredes AJ, Schofs L, Gonzo EE, Palma SD and Bermúdez} JM (2018) Development and in vitro evaluation of solid dispersions as strategy to improve albendazole biopharmaceutical behavior. Therapeutic Delivery 9(9), 623-638.

Spiliotis M and Brehm K (2009) Axenic in vitro cultivation of Echinococcus multilocularis metacestode vesicles and the generation of primary cell cultures. In Rupp S and Sohn K (eds). Host-Pathogen Interactions. Methods in Molecular Biology 470, 245-262.

Thompson DO (1997) Cyclodextrins-enabling excipients: their present and future use in pharmaceuticals. Critical Reviews in Therapeutic Drug Carrier Systems 14(1), 104 .

Ullio Gamboa G, Pensel PE, Elissondo MC, Sanchez Bruni S, Benoit JP, Palma SD and Allemandi DA (2019) Albendazole-lipid nanocapsules: Optimization, characterization and chemoprophylactic efficacy in mice infected with Echinococcus granulosus. Experimental Parasitology 198, 79-86.

Vasconcelos T, Sarmiento B and Costa P (2007) Solid dispersions as strategy to improve oral bioavailability of poor water soluble drugs. Drug Discovery Today 12, 1068-1075.

Vo CLN, Park C and Lee BJ (2013) Current trends and future perspectives of solid dispersions containing poorly water-soluble drugs. European Journal of Pharmaceutics and Biopharmaceutics 85(3), 799-813. 
473 Wen H, Vuitton L, Tuxun T, Li J, Vuitton DA, Zhang W and McManus DP (2019) 32(2), e00075-18.

476

477

478

479

480

481 
482

483

484

485

486

487

488

489

490

491

492

493

494

495

496

497

498

499

500

\section{Legends to figures}

Fig. 1. Scanning electron microscopy of E. multilocularis cysts recovered from infected mice belonging to the chemoprophylactic efficacy study. (A) Control cyst with an intact germinal layer (gl). (B) Cyst recovered from mice treated with ABZ-CMC. Note the loss of cells in the germinal layer. (C) Cyst obtained from treatment with physical mixture. Observe the areas without cells. (D) Germinal layer of metacestode recovered from the ABZ:P407 SDs treated group. Areas with extensive loss of cells can be observed. Scale bar $=50 \mu \mathrm{m}$.

Fig. 2. Scanning electron microscopy of E. multilocularis cysts recovered from infected mice belonging to the clinical efficacy study. (A) Control cyst with an intact germinal layer (gl). (B) Cyst recovered from mice treated with ABZ-CMC. Reduction in the cell number could be observed. (C) Cyst obtained from treatment with physical mixture. Observe areas without cells. (D) Germinal layer of metacestode from ABZ:P407 SDs treated group. Only cellular debris and isolated cells could be observed. Scale bar $=50$ $\mu \mathrm{m}$. 
Table 1

502 Chemoprophylactic efficacy study. Median weight (g) and interquartile range (IQR) of 503 the E. multilocularis cysts recovered from artificially infected mice from the 504 unmedicated control and treated groups. Twenty-four hours post-infection, daily 505 treatments were performed by intragastric administration of different formulations of $506 \mathrm{ABZ}$ at the dose of $25 \mathrm{mg} / \mathrm{kg}$ of $\mathrm{ABZ}$ over a period of 30 days.

\begin{tabular}{lcc} 
& $\begin{array}{c}\text { Median weight } \\
\text { of cysts }(\mathrm{g})\end{array}$ & $\begin{array}{c}\text { Interquartile range } \\
\text { (IQR) }\end{array}$ \\
\hline Water control & 3.62 & 2.53 \\
\hline P407 control & 2.91 & 4.81 \\
\hline ABZ-CMC & 1.72 & 0.91 \\
\hline Physical mixture & 1.05 & 1.53 \\
\hline ABZ:P407 SDs & 0.95 & 1.78 \\
\hline
\end{tabular}

507

508

509

Table 2

510 Clinical efficacy study. Median weight (g) and interquartile range (IQR) of the $E$.

511 multilocularis cysts recovered from artificially infected mice from the unmedicated 512 control and treated groups. Six weeks post-infection, daily treatments were performed 513 by intragastric administration of different formulations of $\mathrm{ABZ}$ at the dose of $25 \mathrm{mg} / \mathrm{kg}$ 514 of $\mathrm{ABZ}$ over a period of 30 day.

Median weight

of cysts (g)
Interquartile range

(IQR) 


\begin{tabular}{lcc} 
Water control & 4.27 & 2.41 \\
\hline P407 control & 3.44 & 2.25 \\
\hline ABZ-CMC & 0.69 & 0.72 \\
\hline Physical mixture & 0.57 & 0.27 \\
\hline ABZ:P407 SDs & $0.28^{*}$ & 0.66 \\
\hline * Statistically significant differences with the control groups $(\mathrm{P}<0.05)$.
\end{tabular}

517

518 

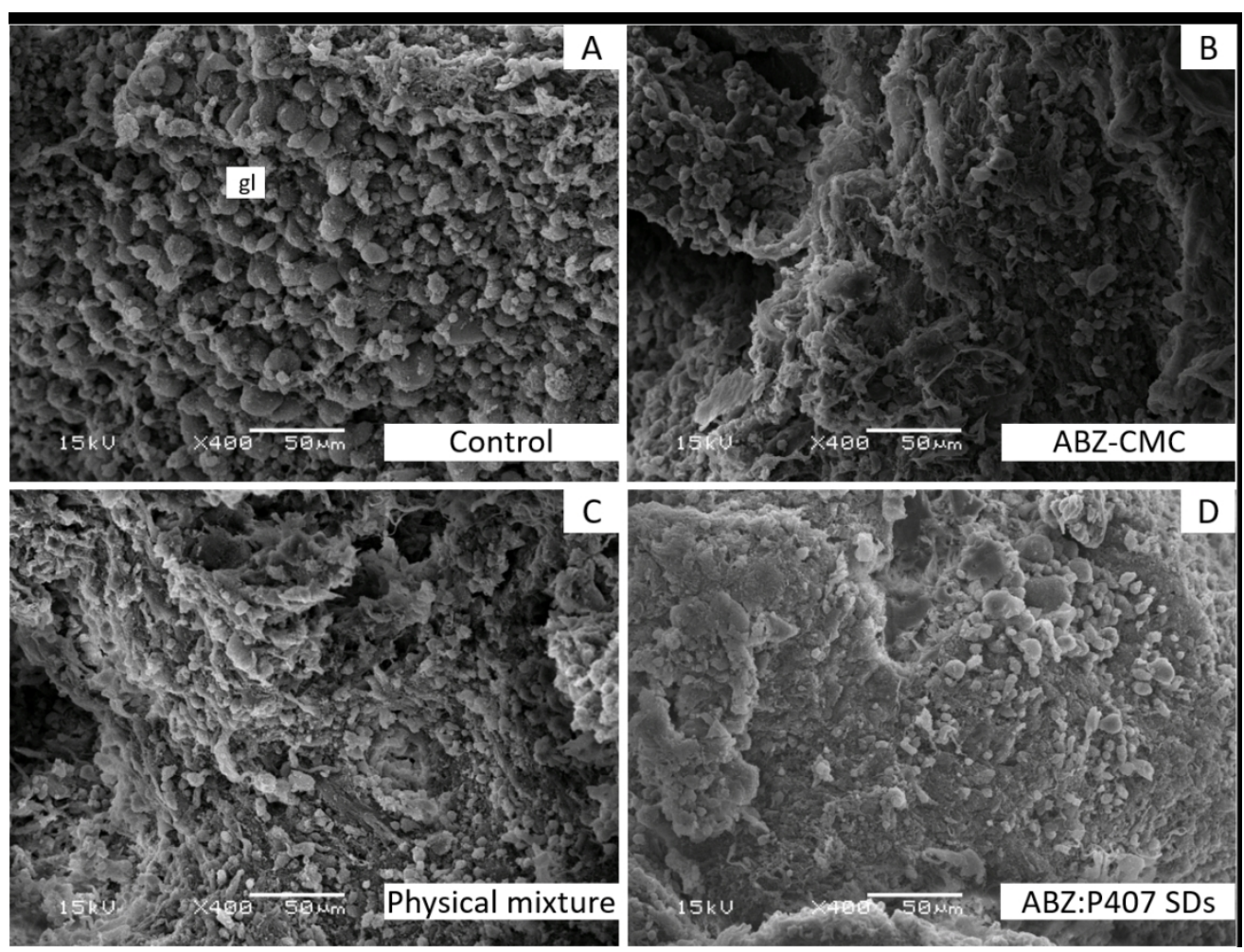

Scanning electron microscopy of $\mathrm{E}$. multilocularis cysts recovered from infected mice belonging to the chemoprophylactic efficacy study. (A) Control cyst with an intact germinal layer ( $\mathrm{gl}$ ). (B) Cyst recovered from mice treated with ABZ-CMC. Note the loss of cells in the germinal layer. (C) Cyst obtained from

treatment with physical mixture. Observe the areas without cells. (D) Germinal layer of metacestode recovered from the ABZ:P407 SDs treated group. Areas with extensive loss of cells can be observed. Scale bar $=50 \mu \mathrm{m}$.

$211 \times 160 \mathrm{~mm}(150 \times 150 \mathrm{DPI})$ 

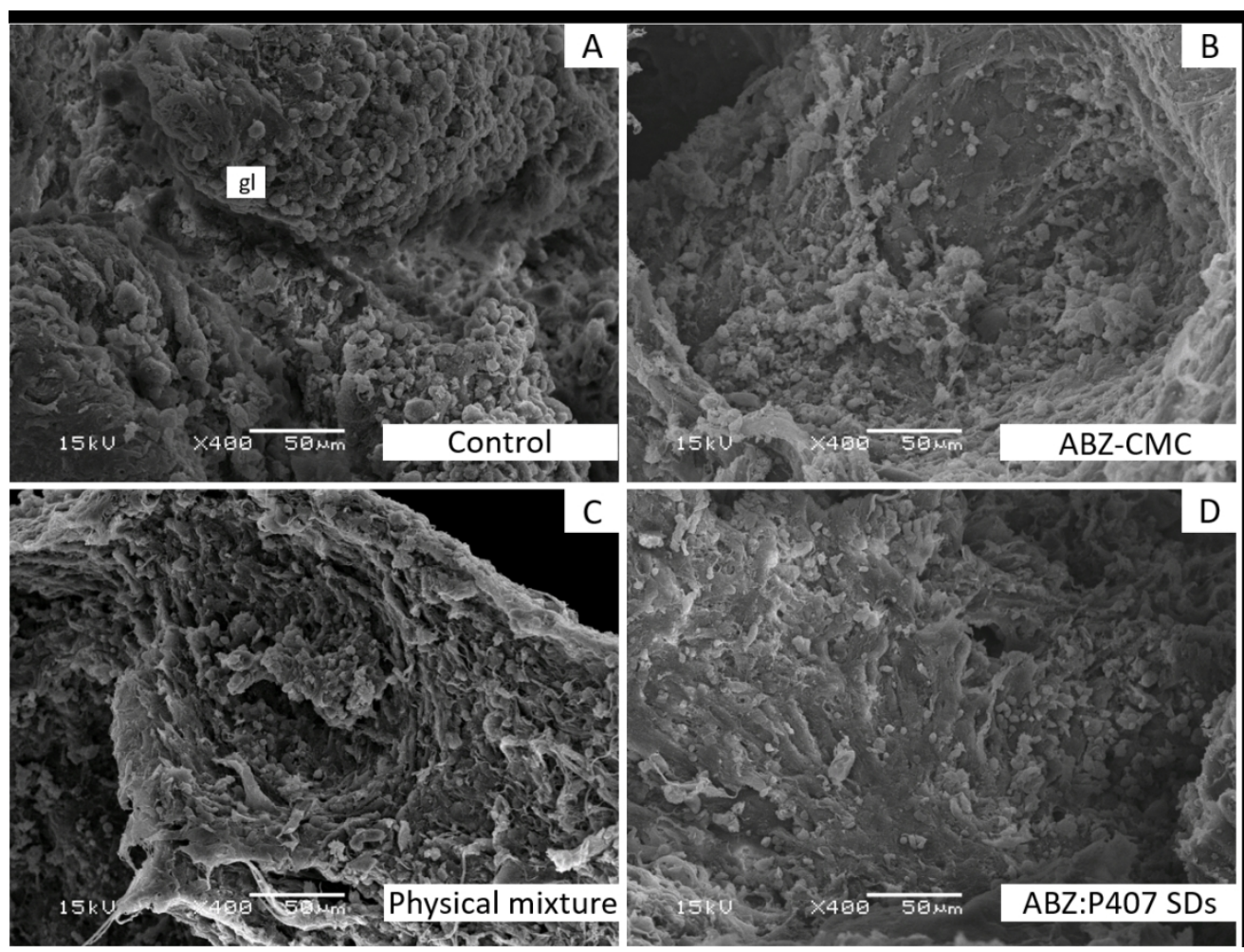

Scanning electron microscopy of E. multilocularis cysts recovered from infected mice belonging to the clinical efficacy study. (A) Control cyst with an intact germinal layer ( $\mathrm{gl}$ ). (B) Cyst recovered from mice treated with ABZ-CMC. Reduction in the cell number could be observed. (C) Cyst obtained from treatment with physical mixture. Observe areas without cells. (D) Germinal layer of metacestode from ABZ:P407 SDs treated group. Only cellular debris and isolated cells could be observed. Scale bar $=50 \mu \mathrm{m}$. 